$\begin{gathered}\text { EPiC Series in Built Environment } \\ \text { Volume 2, 2021, Pages 559-567 } \\ \text { ASC 2021. 57th Annual Associated Schools } \\ \text { of Construction International Conference }\end{gathered}$
Built
Environment

\title{
Evidences of Opportunity Gaps in Construction Management Education
}

\author{
Jared M. Burgoon, Ph.D. and Jonathan W. Elliott, Ph.D. \\ Colorado State University \\ Fort Collins, CO
}

\begin{abstract}
Disparities in bachelor's degree obtainment and academic success as evidence of "opportunity gaps” between underserved racial-ethnic minority, low-income, and first-generation students and their peers is well documented in the United States higher education system. However, academic literature addressing the opportunity gap in construction management education is limited. This study investigated the academic success of Latinx, Pell Grant eligible, and first-generation students as compared to White (non-Latinx), non-Pell Grant eligible, and continuing-generation students at a large U.S. based construction management program for the years 2008 to 2017. Findings indicate that statistically significant differences in grade point average and construction management program eligibility exist between White (non-Latinx) and Latinx students at the construction management program of interest for this study.
\end{abstract}

Key Words: Opportunity gap, Low-income, Minority, First-generation, Construction management

\section{Introduction}

The attainment of a bachelor's degree is an increasingly important milestone for obtaining access to high-demand, well-paying careers like those found in the construction management (CM) industry (BLS, 2020). However, disparities in degree attainment between underserved racial-ethnic minority (URM) students, students from low-income backgrounds, and first-generation students and their respective peers could result in disproportionate access to these well-paying and high-demand professions (Engle \& Tinto, 2008; Ryan \& Bauman, 2016). Academic disparities in the United States (U.S.) higher education system are, at least in part, the result of numerous economic, socio, and political systems that provide some students with more significant and relevant educational opportunities than their peers, thus creating a gap in educational opportunity (i.e., "opportunity gap”) for underserved students (Carter \& Welner, 2013; Ladson-Billings, 2006). Long recognized as a barrier to social mobility, numerous policies ranging from the Morrill Act of 1890 to affirmative action programs have sought to overcome opportunity gaps by increasing college access for underserved student groups (Harper, Patton \& Wooden, 2007). While access is important, recent discussions in higher education have moved beyond college access to include a focus on providing equitable support and opportunity for traditionally underserved student groups (Ching et al., 2020). 
According to Tinto (2012), four conditions maximize the probability of student success in higher education. These include: 1) clear expectations of the requirements for success, 2) social, academic, and financial support, 3) frequent assessments and quality feedback, and 4) social and academic involvement. In an attempt to maximize student success, educational institutions have implemented policies and programs to better support traditionally underserved student groups, particularly during the first few years of enrollment when attrition rates are the highest (Kinzie et al., 2008). Still, URM, low-income, and first-generation students encounter greater social, academic, financial, and cultural barriers than their peers in higher education (Durkee, Perkins \& Hope, 2020; Engle \& Tinto, 2008; Ryan \& Bauman, 2016). For example, URM students enrolled in STEM majors encountered negative stereotyping and a shortage of same-race peers, which have been associated with lower academic success and lower expectations of university graduation (Durkee, Perkins \& Hope, 2020; Strayhorn et al., 2013). First-generation and low-income students, who are disproportionally URM, often have higher work and family demands than their peers. These factors, in conjunction with lower academic preparation, can negatively affect academic success and social engagement at college (Engle \& Tinto, 2008; Stebloeton \& Soria, 2013).

CM education is a field of study in higher education where the investigation of academic opportunity gaps for URM, first-generation, and low-income students is limited. Despite a strong occupational outlook, higher than average starting salaries, and recent increases in the number of URM students pursuing CM degrees, URM enrollment in CM education programs is low in comparison to construction workforce participation, and studies addressing opportunity gaps are minimal (BLS, 2020; Burgoon, 2020; Elliott, Burgoon \& Weisshaar, 2019). Given the resource constraints of most $\mathrm{CM}$ programs and the scarcity of academic studies addressing the opportunity gaps in CM education, it is important for CM programs to identify where and if opportunity gaps exist in CM education as a means of efficiently providing equitable support and opportunity for underserved student groups.

\section{Research Purpose and Questions}

This study investigated the academic outcomes of undergraduate CM students enrolled at a large university in the United States (U.S.) during their first four semesters (two years) after university matriculation. Specifically, the researchers analyzed student grade point averages (GPA) and evaluated whether students were eligible for admission into an undergraduate CM program to identify evidences of academic opportunity gaps. It should be noted that the CM program of interest for this study requires students to enroll in the CM program in a probationary manner and then meet certain academic criteria in order to be admitted into the program (see CM Program and Populations of Interest described below). Given the availability of institutional data, the demographic characteristics of the CM program population, and the target sample sizes required for analysis, this study compared the academic successes of Latinx (the largest URM group in the U.S. and the CM program of interest), Pell Grant eligible (Pell eligible), and first-generation students with their peers.

The following research questions were developed based on academic outcome variables shown in the literature to inform opportunity gaps in university academic programs:

RQ1: Is a significant difference in first year (e.g. end of second semester) cumulative GPA observed between Latinx and White (non-Latinx) CM students in the program of interest?

RQ2: Is a significant difference in second year (e.g. end of fourth semester) cumulative GPA observed between Latinx and White (non-Latinx) CM students in the program of interest? 
RQ3: Is a significant difference in CM program eligibility observed between Latinx and White (non-Latinx) CM students at the end of the first academic year (e.g. end of second semester) RQ4: Is a significant difference in CM program eligibility observed between Latinx and White (non-Latinx) CM students at the end of the second academic year (e.g. end of fourth semester) RQ5: Is a significant difference in first year (e.g. end of second semester) cumulative GPA observed between Pell-eligible and non-Pell-eligible CM students in the program of interest? RQ6: Is a significant difference in first year (e.g. end of second semester) cumulative GPA observed between Pell-eligible and non-Pell-eligible CM students in the program of interest? RQ7: Is a significant difference in CM program eligibility observed between Pell-eligible and non-Pell-eligible CM students at the end of the first academic year (e.g. end of second semester) RQ8: Is a significant difference in CM program eligibility observed between Pell-eligible and non-Pell-eligible CM students at the end of the second academic year (e.g. end of fourth semester)

RQ9: Is a significant difference in first year (e.g. end of second semester) cumulative GPA observed between first and continuing-generation CM students in the program of interest? RQ10: Is a significant difference in first year (e.g. end of second semester) cumulative GPA observed between first and continuing-generation CM students in the program of interest? RQ11: Is a significant difference in CM program eligibility observed between first and continuing-generation CM students at the end of the first academic year (e.g. end of second semester)

RQ12: Is a significant difference in CM program eligibility observed between first and continuing-generation CM students at the end of the second academic year (e.g. end of fourth semester)

\section{Methodology}

\section{Dataset, CM Program, and Populations of Interest}

Existing anonymized (i.e., Institution Review Board exempt) academic performance data were provided by the Department of Institutional Research (IR) at the university under study. The IR data contained demographic and academic performance data (e.g., semester and cumulative GPA, university persistence, etc.) for all university students that formally pursued CM as their primary academic major for at least one semester between the years 1990 and 2017.

The CM program of interest for this study is part of a land grant university in the western U.S. During the Fall semester of 2017, the CM program of interest had a total of 795 declared undergraduate students which consisted of CM $(n=514)$ and Pre-CM $(n=281)$ students. The program of interest is a capped and controlled program and specific academic criteria must be met prior to admission. As of 2008, admission into the CM program requires a minimum cumulative GPA of 2.75 at the university under study (i.e., GPA from other colleges or universities is not a consideration in CM program admission). Prior to official admission into the CM program, students who wish to major in CM are designated as Pre-Construction Management (Pre-CM).

The population of interest for this study was delimited to Pre-CM cohort majors (i.e., students that declared Pre-CM at university matriculation) that enrolled in the university between the years of 2008 and 2015. As data were only available until 2017, these delimitations allowed for the analysis of all cohort CM students that enrolled since the admissions criteria were implemented while still providing a full two years of academic data. 


\section{Data Analysis}

Independent samples t-test were utilized to compare the mean cumulative GPA of Latinx and White (non-Latinx) (RQ1 and RQ2), Pell-eligible and non-Pell-eligible (RQ5 and RQ6), and first-generation and continuing-generation (RQ9 and RQ10) student groups at the end of the first year (e.g. second semester) and second year (e.g. fourth semester) of enrollment, respectively. These analyses investigated a statistically significant $(\mathrm{P}<0.05)$ difference in student's first year and second year cumulative GPA after matriculation at the university under study. It should be noted that if a student did not enroll during their second or fourth semesters after matriculation, their cumulative GPA was excluded from analysis. Furthermore, cumulative GPA was limited to students' GPA while attending the university under study (i.e., GPA data from other colleges or universities was excluded analysis).

Pearson Chi-Square tests were utilized to compare the CM program eligibility of Latinx and NonLatinx (RQ3 and RQ4), Pell eligible and non-Pell eligible (RQ7 and RQ8), and first-generation and continuing-generation (RQ11 and RQ12) student groups during the first and second years of enrollment. For these analyses, students were coded into the dichotomous categories of "eligible" or "ineligible” for CM program admission. Students coded as "eligible” met two criteria: 1) a minimum cumulative GPA of 2.75 at the university under study and 2) enrollment at the university under study during their second or fourth semesters after matriculation. Students that did not meet these two criteria were coded as “ineligible.” Mean statistics for each group for semesters one through four were compiled in graphs with a 2.75 GPA benchmark to provide a visual representation of the longitudinal data.

\section{Results}

\section{White (non-Latinx) and Latinx Comparison}

An independent samples t-test (Table 1 ) reveals that were no statistically significant differences between Latinx $(n=56)$ and White (non-Latinx) $(n=597)$ students' average GPA after the first year $(\mathrm{p}=.100)$. However, further analysis reveals that were statistically significant differences between Latinx $(n=49)$ and White (non-Latinx) $(n=523)$ students' average GPA after the second year $(p=$ .003). Evaluation of the two populations during their second year indicates that the mean GPA of Latinx students (2.73) is significantly lower than White (non-Latinx) students (2.97).

Table 1

Comparison of White (non-Latinx) and Latinx Students First and Second Year GPA

\begin{tabular}{lcccccc}
\hline Cumulative GPA & $N$ & $M$ & $S D$ & $t$ & $d f$ & $p$ \\
\hline First Year GPA & & & & -1.69 & 651 & .100 \\
Latinx & 56 & 2.65 & .63 & & & \\
White (non-Latinx) & 597 & 2.81 & .69 & & & .003 \\
Second Year GPA & & & & -2.96 & 570 & \\
Latinx & 49 & 2.73 & .52 & & & \\
White (non-Latinx) & 523 & 2.97 & .54 & & & \\
\hline
\end{tabular}

A descriptive analysis of cumulative GPA averages by semester for the years 2008 to 2017 for Latinx and White (non-Latinx) students (Figure 1) shows a difference of 0.14 points (4-point scale) in cumulative GPA existed between Latinx and White (non-Latinx) after one semester. This gap 
increases during the second semester and third semesters, before falling to a 0.24 point gap during students' fourth semester.

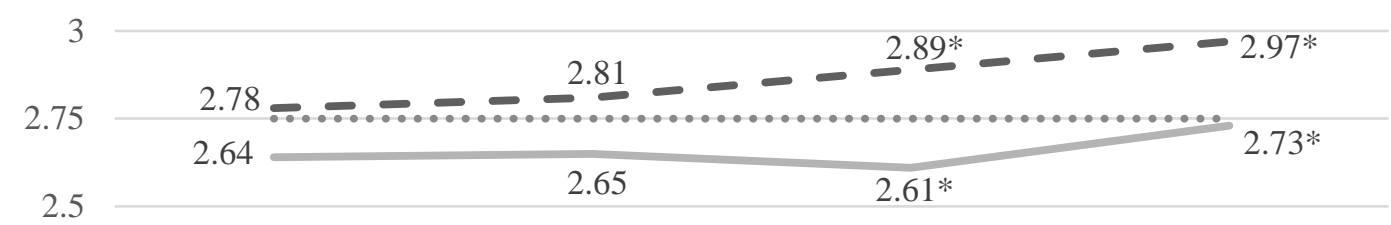

First Semester GPA Second Semester GPA Third Semester GPA Fourth Semester GPA

- - White (non-Latinx) Latinx …. CM Admission Threshold

Figure 1. Mean cumulative GPA of White (non-Latinx) and Latinx students

Chi-square statistics were conducted to investigate whether White (non-Latinx) $(n=618)$ and Latinx ( $n=62$ ) students differ in terms of CM program admission eligibility during their first and second years after matriculation. Results indicate that there are significant differences between White (nonLatino) and Latino student $\mathrm{CM}$ program admission eligibility during their first $\left(\chi^{2}=6.70, \mathrm{df}=1, \mathrm{~N}=\right.$ $680, \mathrm{p}=.010)$ and second $(\chi 2=8.99, \mathrm{df}=1, \mathrm{~N}=680, \mathrm{p}=.003)$ years of enrollment.

As shown in Figure 2, 57\% of White (non-Latinx) and 40\% of Latinx students are eligible for CM program admission after their first year; with a slightly widening gap of $57 \%$ of White (non-Latins) and $37 \%$ of Latins students are eligible for CM program admission after their second year.

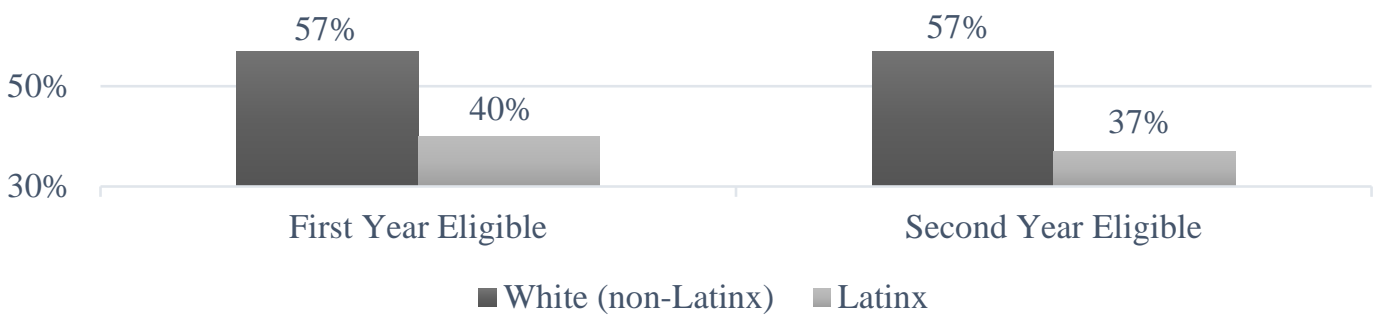

Figure 2. White (non-Latinx) and Latinx students eligible for CM program admission

\section{Non-Pell Eligible and Pell Eligible Comparison}

Independent samples t-tests (Table 2) reveal that were not statistically significant differences between non-Pell eligible $(n=577)$ and Pell eligible $(n=145)$ students' average GPA after the first year $(p=$ .489) and no statistically significant differences existed between non-Pell eligible $(n=507)$ and Pell eligible $(\mathrm{n}=124)$ students' average GPA after the second year $(\mathrm{p}=.897)$.

Table 2

Comparison of Pell Eligible and Non-Pell Eligible Students Second and Fourth Semester GPA

\begin{tabular}{ccccccc}
\hline Cumulative GPA & $N$ & $M$ & $S D$ & $t$ & $d f$ & $p$ \\
\hline First Year GPA & & & & .70 & 720 & .489 \\
Non-Pell Eligible & 577 & 2.81 & .68 & & & \\
Pell Eligible & 145 & 2.78 & .70 & & &
\end{tabular}


Second Year GPA

Non-Pell Eligible

Pell Eligible

\begin{tabular}{lll}
507 & 2.95 & .54 \\
124 & 2.96 & .51 \\
\hline
\end{tabular}

629

.897

A descriptive analysis of cumulative GPA averages by semester for the years 2008 to 2017 for Pell and non-Pell eligible students (Figure 3) shows a difference of 0.03 points (4-point scale) in cumulative GPA existed between Pell and non-Pell eligible students after one semester. As shown, both Pell and non-Pell eligible students' cumulative GPAs were similar over the four semesters.

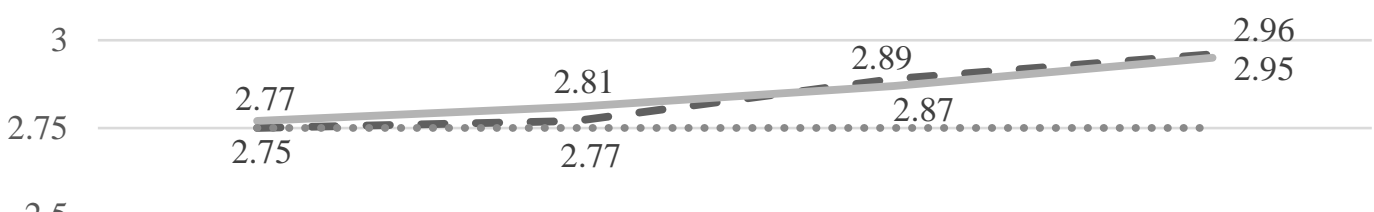

First Semester GPA Second Semester GPA Third Semester GPA Fourth Semester GPA

- Pell Eligible $\quad$ Non-Pell Eligible ...... CM Admission Threshold

Figure 3. Mean GPA of Pell eligible and non-Pell eligible students

Chi-square statistics were conducted to investigate whether Pell eligible $(n=151)$ and non-Pell eligible $(n=602)$ students differ in terms of CM program admission eligibility during their first and second years after matriculation. Results indicate that there are no significant differences between Pell eligible and non-Pell eligible student CM program admission eligibility during the first $\left(\chi^{2}=.232\right.$, df $=1, \mathrm{~N}=753, \mathrm{p}=.630)$ and second $\left(\chi^{2}=.196, \mathrm{df}=1, \mathrm{~N}=753, \mathrm{p}=.658\right)$ years.

As shown in Figure 4, 54\% of Pell eligible and 57\% of non-Pell eligible students are eligible for CM program admission during their second semester; with a near static gap of 54\% of Pell eligible and $56 \%$ of non-Pell eligible students eligible for CM program admission during their fourth semester.

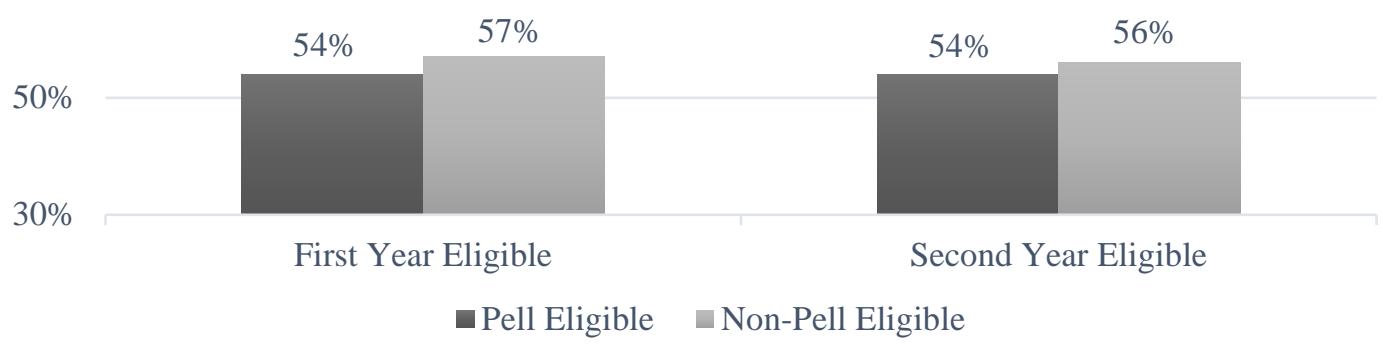

Figure 4. Pell eligible and non-Pell eligible students eligible for CM program admission

\section{First-generation and Continuing-generation Comparison}

An independent samples t-test (Table 3) reveals that there were not statistically significant differences between continuing-generation $(n=525)$ and first-generation $(n=197)$ student's average GPA during the first year $(p=.646)$. Furthermore, there were not statistically significant differences between continuing gen $(n=464)$ and first-generation $(n=167)$ student's average GPA during the second year $(p=.436)$. 
Table 3

Comparison of Continuing and First Generation Students Second and Fourth Semester GPA

\begin{tabular}{ccccccc} 
Cumulative GPA & $N$ & $M$ & $S D$ & $t$ & $d f$ & $p$ \\
\hline First Year GPA & & & & .46 & 720 & .646 \\
Continuing-generation & 525 & 2.81 & .69 & & & \\
$\quad$ First-generation & 197 & 2.78 & .66 & & & .436 \\
Second Year GPA & & & & .779 & 629 & \\
$\quad$ Continuing-generation & 464 & 2.96 & .55 & & & \\
First-generation & 167 & 2.92 & .49 & & & \\
\hline
\end{tabular}

A descriptive analysis of cumulative GPA averages by semester for the years 2008 to 2017 for continuing and first-generation students (Figure 5) shows a difference of 0.02 points (4-point scale) in average cumulative GPA existed between continuing and first-generation students after one semester. As shown, the 0.02 was consistent for the first two semesters before increasing to 0.05 during the third and fourth semesters. Even so, the overall trend remained relatively constant over the four semesters.

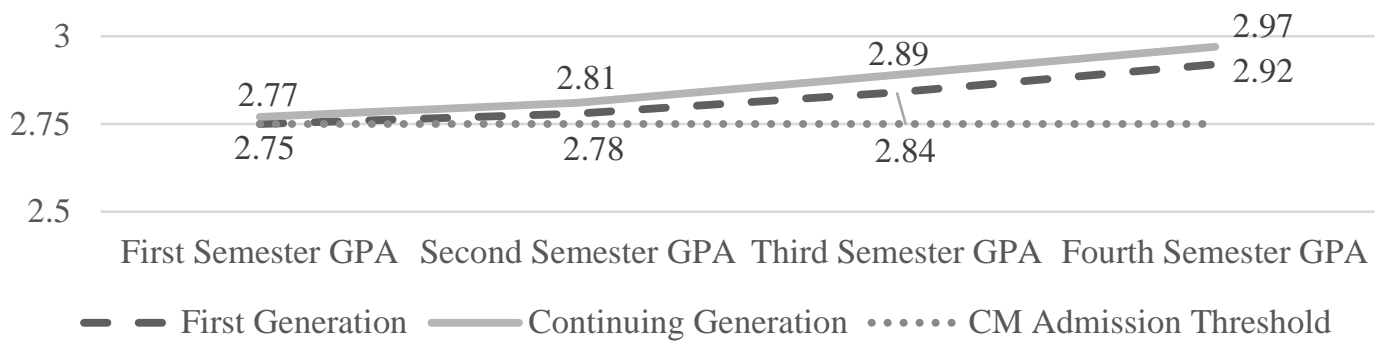

Figure 5. Mean GPA of first-generation and continuing-generation students

Chi-square statistics were conducted to investigate whether first-generation $(n=208)$ and continuinggeneration $(n=545)$ students differ in terms of CM program admission eligibility after their first and second years. Results indicate that there are no significant differences between first-generation and continuing-generation student CM program admission eligibility during the second $\left(\chi^{2}=.836, \mathrm{df}=1\right.$, $\mathrm{N}=753, \mathrm{p}=.361)$ and fourth $\left(\chi^{2}=3.198, \mathrm{df}=1, \mathrm{~N}=753, \mathrm{p}=.074\right)$ semesters of enrollment.

As shown in Figure 6, 53\% of first-generation and 57\% of continuing-generation students are eligible for CM program admission during their second semester; with a slightly widening gap of 50\% of firstgeneration and 57\% of continuing-generation students are eligible for CM program admission during their fourth semester.

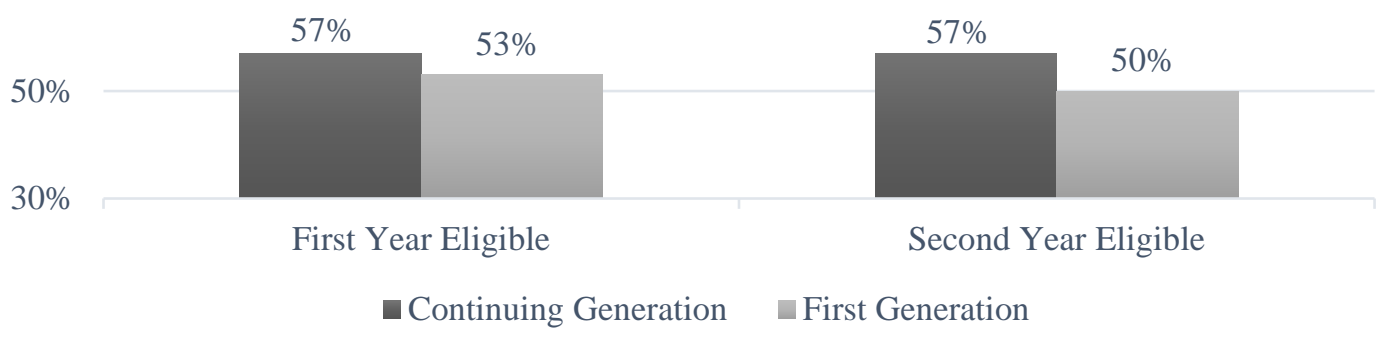


Figure 6. First-generation and continuing-generation students eligible for CM program admission

\section{Discussion and Conclusion}

The purpose of this study was to conduct a CM-specific investigation of academic performance metrics that are shown in literature to provide evidence of the manifestation of an opportunity gap for URM, low-income, and first-generation students in higher education. Results indicate that no statistically significant differences exist between non-Pell eligible and Pell eligible students or first and continuing-generation students in first and second year average cumulative GPA or first and second year CM program eligibility at the program of interest. Conversely, significant differences exist between White (non-Latinx) and Latinx students in first and second year CM program eligibility and second year average cumulative GPA and provide evidence of a White (non-Latinx) to Latinx opportunity gap in CM education.

It is important to note that while this study can serve as a baseline and guide for future research on potential opportunity gaps in CM education, the existence, or lack, of academic disparities in the CM program of interest do not provide certainty that an opportunity gap exists. The results of this study provide face validation that further research exploration of the manifestation of opportunity gaps in CM education is warranted.

A deeper understanding of disparities in academic performance metrics among CM students will likely require a nuanced and comprehensive approach focused on identifying barriers to success in academia at the individual level. The investigation of the intersection of individual characteristics and situations may provide deep and valuable insight into the existence of opportunity gaps in CM programs. With a more clear and thorough understanding of barriers to student success, CM programs can make informed decisions that impact policy and programs with the goal of promoting student success.

\section{Future Research and Limitations}

Since the data utilized in this study is likely accessible through university IR departments, replication or multi-university studies could yield more generalizable results. Future studies could also evaluate the effects of intersecting characteristics (e.g., race and gender) have on evidences of opportunity gaps. The utilization of qualitative or mixed methods methodologies in future studies could also be beneficial in understanding the potential causes of the disparities identified in this study. Furthermore, given the likelihood of a relatively small number of individuals with multiple minority characteristics (e.g., Latina women) that are currently enrolled in CM, quantitative methodologies are likely limited until a critical mass of these students is formed. Future research could also explore if specific academic courses (e.g., math, language composition) are disproportionally generating disparities.

The followings limitations should be assessed when interpreting the findings of this study. First, data for this study were delimited to CM cohort majors at a single institution in the U.S. As such, generalizability is limited and evidences of opportunity gaps for students that transferred to CM after matriculation are not accessed. This study also utilized secondary data that contained self-reported demographic variables which could not be independently verified by the researchers; therefore, assumptions of accuracy were assumed. 


\section{References}

Bureau of Labor Statistics (BLS), U.S. Department of Labor, Occupational Outlook Handbook, Construction Managers, Retrieved from: https://www.bls.gov/ooh/management/constructionmanagers.htm.

Burgoon, J. (2020). Exploring the equity climate of construction education in the land grant system: a mixed methods study. Colorado State University. Libraries.

Carter, P. L., \& Welner, K. G. (Eds.). (2013). Closing the opportunity gap: What America must do to give every child an even chance. Oxford University Press.

Ching, C. D., Felix, E. R., Fernandez Castro, M., \& Trinidad, A. (2020). Achieving racial equity from the bottom-up? The student equity policy in the California community colleges. Educational Policy, 34(6), 819-863.

Durkee, M. I., Perkins, T. R., \& Hope, E. C. (2020). Academic affect shapes the relationship between racial discrimination and longitudinal college attitudes. Social Psychology of Education, 1-16.

Elliott, J., Burgoon, J., \& Weisshaar, M. (2019). Exploring gender and ethnic diversity recruitment goals: Comparing 2007-2017 CM education and industry trends. In 55th ASC Annual International Conference, Denver, CO.

Engle, J., \& Tinto, V. (2008). Moving beyond access: College success for low-income, firstgeneration students. Pell Institute for the Study of Opportunity in Higher Education.

Harper, S. R., Patton, L. D., \& Wooden, O. S. (2009). Access and equity for African American students in higher education: A critical race historical analysis of policy efforts. The Journal of Higher Education, 80(4), 389-414.

Kinzie, J., Gonyea, R., Shoup, R., \& Kuh, G. D. (2008). Promoting persistence and success of underrepresented students: Lessons for teaching and learning. New Directions for Teaching and Learning, 2008(115), 21-38.

Ladson-Billings, G. (2006). From the achievement gap to the education debt: Understanding achievement in US schools. Educational researcher, 35(7), 3-12.

Ryan, C. L., \& Bauman, K. (2016). Educational attainment in the United States: 2015 population characteristics. United States Census Bureau, 2010, 20-578.

Stebleton, Michael \& Soria, Krista. (2013). Breaking down barriers: Academic obstacles of firstgeneration students at research universities. The Learning Assistance Review. Retrieved from the University of Minnesota Digital Conservancy, http://hdl.handle.net/11299/150031.

Strayhorn, T. L., Long, L. L., III, Kitchen, J. A., Williams, M. S., \& Stentz, M. (2013). Academic and social barriers to Black and Latino male collegians' success in engineering and related STEM fields. Proceedings from 2013 ASEE Annual Conference and Exposition, Atlanta, GA.

Tinto, V. (2012). Moving from theory to action. In Seidman, A. (2012). College Student Retention: Formula for Student Success. Rowman \& Littlefield Publishers. 